\title{
ALIMENTOS TRADICIONAIS, MODOS DE VIDA E PATRIMÔNIO CULTURAL: uma reflexão a partir do Queijo Serrano
}

\author{
TRADITIONAL FOOD, WAY OF LIFE AND CULTURAL HERITAGE: a \\ reflexion from Serrano Cheese
}

\section{MODOS DE VIDA, ALIMENTOS TRADICIONALES Y PATRIMONIO CULTURAL: una reflexión a partir del Queso Serrano}

\author{
Fabiana Thomé da Cruz \\ Engenheira de Alimentos, Doutora em Desenvolvimento Rural, \\ Pesquisadora Associada ao Programa de Pós-Graduação em Desenvolvimento \\ Pesquisadora Associada ao Programa de Pós-Graduação em \\ Desenvolvimento Rural - Universidade Federal do Rio Grande do Sul \\ Av. João Pessoa, 31, CEP 90040-000. Porto Alegre/RS - Brasil \\ E-mail: fabianathomedacruz@gmail.com

\section{Renata Menasche} \\ Professora do Instituto de Ciências Humanas da Universidade \\ Federal de Pelotas e do Programa de Pós-Graduação em Desenvolvimento \\ Rural da Universidade Federal do Rio Grande do Sul \\ E-mail: renata.menasche@pq.cnpq.br
}

\begin{abstract}
Resumo
Neste artigo, partimos do pressuposto de que a produção de alimentos tradicionais, imbricada ao modo de vida das famílias produtoras, diz respeito ao cuidado com a terra e ao manejo do gado, mobilizando, para tanto, conhecimentos e práticas específicas, compartilhadas entre os produtores. Tendo como objetivo aprofundar essa discussão, tomamos como objeto de análise o caso do Queijo Serrano, um queijo produzido de modo artesanal, a partir de leite cru, na região dos Campos de Cima da Serra, Rio Grande do Sul. Os dados empíricos analisados são referentes a pesquisa de campo etnográfica conduzida na região de estudo entre os meses de abril e agosto de 2010. Argumentamos que o conhecimento e as práticas tradicionais estão fortemente associados ao manejo das unidades produtivas, bem como à produção e processamento de alimentos, elementos constitutivos de características culturais compartilhadas e modos de vida que, em alguns casos, podem ser pensados em termos de patrimônio cultural.
\end{abstract}

Palavras-chave: queijos de leite cru, produtos artesanais, campesinato, conhecimentos tradicionais. 


\begin{abstract}
In this article, we assume that the production of traditional foods, which is closely related to lifestyle of producer families, concerns to the care for the land and to the cattle management. To this end, those families mobilise specific knowledge and practices, shared among them. In order to further this discussion, we take the case of Serrano Cheese, an artisanal cheese made from unpasteurised milk in Campos de Cima da Serra, Rio Grande do Sul. The empirical data analysed are from an ethnographic field research carried out in the study region between April and August 2010. We argue that the traditional knowledge and practices are strongly associated with the family farm management as well as the food production and processing. These constitutive elements are related to the shared cultural characteristics and to the family farm lifestyles which, in some cases, can be thought of in terms of cultural heritage.
\end{abstract}

Keywords: raw milk cheeses, artisanal products, peasantry, traditional knowledge.

\title{
Resumen
}

En este artículo, partimos del presupuesto de que la producción de alimentos tradicionales, imbricada al modo de vida de las familias productoras, está relacionada al cuidado con la tierra y al manejo del ganado, movilizando, para tanto, conocimientos y prácticas específicas, compartidas entre los productores. Teniendo como objetivo profundizar esa discusión, tomamos como objeto de análisis el caso del Queso Serrano, un queso producido de modo artesanal, a partir de la leche cruda, en la región de los Campos de Cima da Serra, Rio Grande do Sul. Los datos empíricos analizados son referentes a la investigación de campo etnográfica, conducida en la región de estudio entre los meses de Abril y Agosto de 2010. Argumentamos que el conocimiento y las prácticas tradicionales están fuertemente asociados al manejo de las unidades productivas, bien como a la elaboración y procesamiento de alimentos, elementos constitutivos de características culturales compartidas y modos de vida que, en algunos casos, pueden ser pensados en términos de patrimonio cultural.

Palabras clave: quesos de leche cruda, productos artesanales, campesinado, conocimientos tradicionales.

\section{Introdução}

Este artigo toma como ponto de partida o entendimento de que a produção de alimentos tradicionais está imbricada ao modo de vida das famílias produtoras e que conhecimentos e práticas compartilhadas, associadas a formas específicas de cuidado com a terra e ao manejo dos animais, conformam sistema em que várias dimensões da produção, do trabalho e da vida estão articuladas. Buscando explorar as relações entre produção de alimentos tradicionais e modos de vida, tomamos como objeto de análise o caso da produção de Queijo Serrano, um queijo produzido de forma artesanal, a partir 
de leite cru, na região dos Campos de Cima da Serra, localizada no nordeste do Rio Grande do Sul.

O trabalho de campo, fundamentado em pesquisa etnográfica, priorizou a observação participante e entrevistas com produtores, consumidores, técnicos e comerciantes de queijo, com a finalidade apreender experiências, características e detalhes que constituem os modos de vida de produtores de queijo dos Campos de Cima da Serra, as relações deles com outros moradores da região, com consumidores, com comerciantes de queijo e com técnicos. Esses grupos - produtores, consumidores, comerciantes e técnicos - foram definidos antes do trabalho de campo e referem-se à posição que os principais interlocutores da pesquisa assumem em relação ao queijo nos municípios da região em que a pesquisa foi conduzida. Esses municípios foram Bom Jesus, Jaquirana, São Francisco de Paula e São José dos Ausentes. A fase de imersão em campo aconteceu entre os meses de abril e agosto de 2010, período que foi precedido por visitas de curta duração a municípios da região dos Campos de Cima da Serra.

Para a seleção dos interlocutores da pesquisa, o critério de aproximação e seleção foi baseado no princípio de redes sociais, como proposto por Barnes (1987). Desse modo, ao longo do trabalho de campo buscou-se chegar aos técnicos e comerciantes e especialmente às famílias de produtores e consumidores por meio de alguém já conhecido.

No caso da maioria dos produtores e de alguns consumidores, as entrevistas foram realizadas com a presença do casal e, em todos os casos, nas residências das famílias entrevistadas. Foram realizadas 10 entrevistas junto a produtores e 11 entrevistas junto a consumidores. No caso dos técnicos, as seis entrevistas realizadas - à exceção de uma, realizada na casa do interlocutor - foram conduzidas nos locais de trabalho. Já os contatos com comerciantes foram realizados em suas residências, em alguns casos o próprio local de comercialização. Junto a esses interlocutores, foram realizadas três entrevistas. Além dessas entrevistas, que foram gravadas e posteriormente transcritas, várias conversas e visitas informais também foram realizadas. Nesse caso, o conteúdo foi registrado no diário de campo.

Todas as entrevistas, bem como o diário de campo, foram transcritos, conformando dados que foram inseridos no software NVIVO $8^{1}$. Em seguida, todo o

\footnotetext{
${ }^{1}$ Para mais informações, acessar <http://www.qsrinternational.com/other-languages_portuguese.aspx> .
} 
material foi sistematizado em categorias estabelecidas à medida que o material ia sendo transcrito.

Ao longo deste trabalho, para preservar a identidade dos interlocutores, seus nomes foram substituídos por nomes fictícios.

Este artigo está organizado em seis seções. Após esta introdução, apresentaremos algumas características da região produtora de Queijo Serrano no Rio Grande do Sul para, então, discutir a centralidade do gado não apenas na organização das propriedades como também em atividades sociais e de lazer. Nos itens subsequentes, abordaremos as práticas e formas de manejo empregadas por produtores de Queijo Serrano, a centralidade da terra e a preocupação com a natureza para, então, discutirmos a relação entre conhecimentos tradicionais e patrimônio cultural. Por fim, apresentamos algumas considerações finais.

\section{Queijo Serrano: um produto tradicional dos Campos de Cima da Serra}

O Queijo Serrano vem sendo produzido nos Campos de Cima da Serra ${ }^{2}$ (ver Figura 1) há mais de 200 anos. A região possui características específicas, como presença de campos nativos, elevadas altitudes e estações bem definidas ao longo do ano, com invernos com temperaturas baixas, ocorrência frequente de geadas e, ocasionalmente, de neve. O saber-fazer do Queijo Serrano, produzido por famílias rurais, manteve boas partes de suas características preservadas ao ser transmitido de geração em geração. Até os dias atuais, sua fabricação se dá a partir do uso de leite cru, ordenhado de vacas comuns, de raças predominantemente de gado de corte, criadas em sistema extensivo e alimentadas basicamente em campo nativo - especialmente na primavera e verão, quando os campos estão verdes e ricos em nutrientes. Produzido, na maioria das propriedades, em estrutura de madeira, contígua ao galpão, com o emprego de utensílios também de madeira, este queijo é, em geral, consumido após aproximadamente quinze a vinte dias de maturação, quando apresenta como principais características sabor acentuado, massa firme e coloração amarelada.

\footnotetext{
${ }^{2}$ A produção de Queijo Serrano se estende à região serrana do Estado de Santa Catarina. Neste artigo, contudo, tomamos por referência apenas o Queijo Serrano produzido nos Campos de Cima da Serra, Rio Grande do Sul, onde a pesquisa de campo foi conduzida.
} 


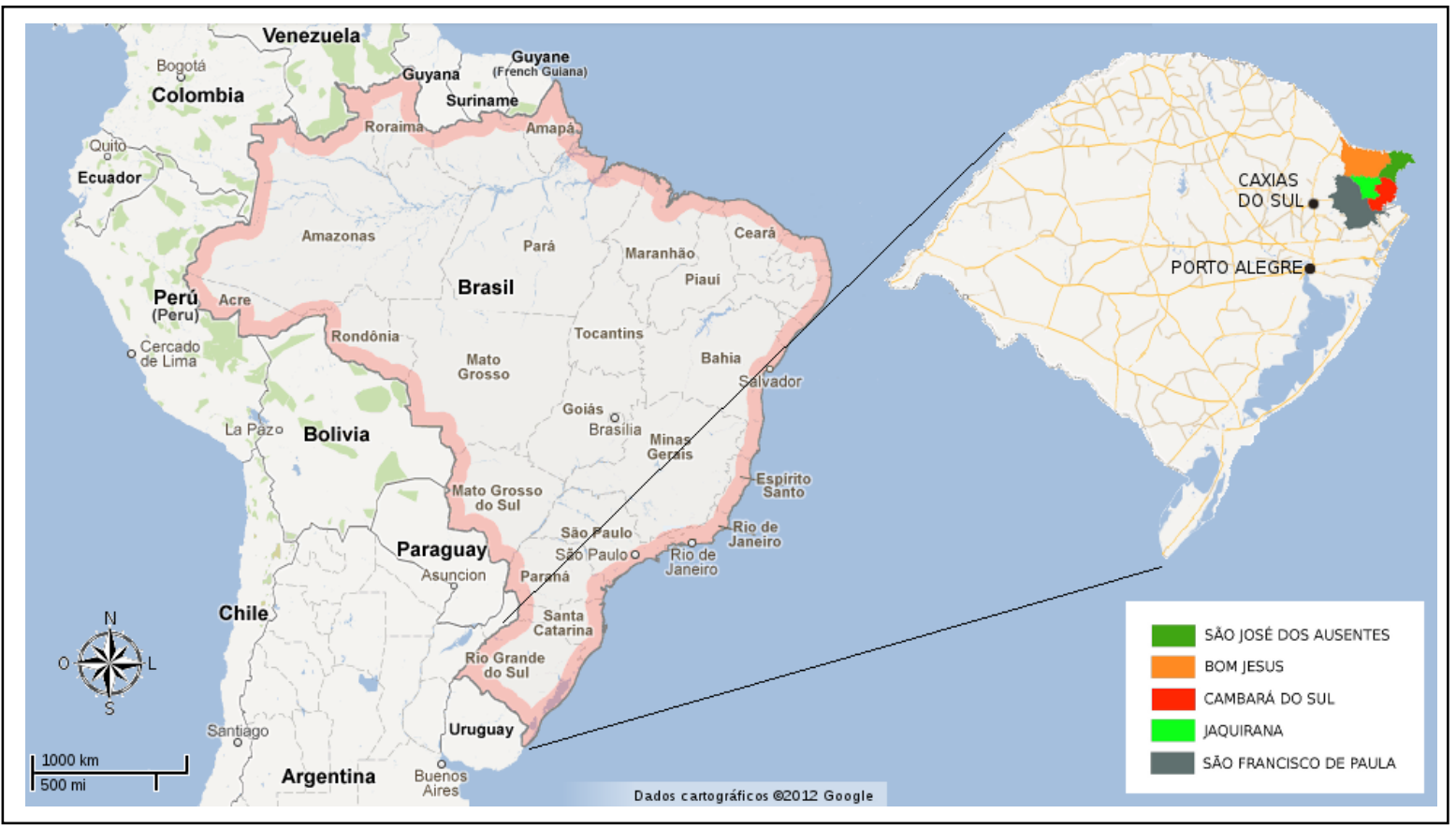

Figura 1: Mapa ilustrativo destacando municípios pertencentes à Região dos Campos de Cima. da Serra, Rio Grande do Sul.

Fonte: Adaptação de Google Mapas, 2012, cedida por Luís Fernando Heckler.

Inicialmente, o manejo das vacas tinha o objetivo de suprir de leite as famílias e, ao manter os terneiros junto às mães durante a ordenha, também de amansar o gado que, por passar o inverno nas encostas de morro, era comumente bastante xucro (Krone, 2009; 2010). Daí a origem da produção do queijo que, até a algumas décadas, era produzido apenas na primavera e verão, quando as pastagens nativas são abundantes. A comercialização era realizada principalmente em cidades próximas e o transporte feito sobre o lombo de mulas que, organizadas em tropas, levavam queijo e outros produtos da região - como couro e pinhão - para, na volta, trazer o que ali não era produzido, como sal, açúcar, farinha de mandioca, etc.

Atualmente, a comercialização de Queijo Serrano ocorre nas cidades da região, por meio de venda direta ou em pequenos mercados locais. Devido à boa reputação e notoriedade desse queijo e, especialmente de alguns produtores, em alguns casos os consumidores deslocam-se até as propriedades produtoras para buscar queijo; em outros, comerciantes de queijo - ou atravessadores, como são conhecidos na região - adquirem-no de produtores, para revender. 


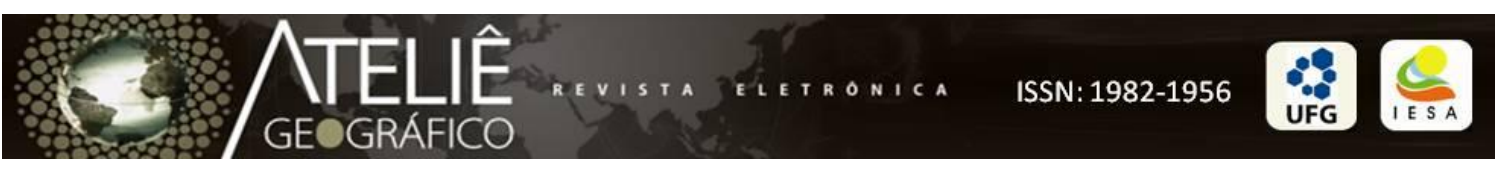

Apesar de, atualmente, muitas famílias produzirem queijo durante o ano todo, o fazem em pequena escala: desconsiderando as variações sazonais, pode-se dizer que, em geral, cada família produz, em um dia, de quatro a oito quilos de queijo, o que representa quarenta a oitenta litros de leite processados. Ainda que atividade secundária (para a grande maioria das famílias rurais da região, a pecuária é a principal atividade econômica), a produção de queijo representa renda significativa, pois com ela são pagas as despesas da casa. Ainda, tão importante quanto seu papel na garantia da renda para as famílias produtoras, a produção desse queijo diz respeito também a seu modo de vida, fortemente associado aos cuidados com a terra e ao manejo do gado.

\section{A lavoura, o gado e seus significados}

Em uma das primeiras visitas à região dos Campos de Cima da Serra, escutando um produtor que explicava aspectos referentes a sua propriedade, foi possível perceber que, quando ele se referia à lavoura, falava da pastagem que, diferentemente do campo nativo, diz respeito à pastagem cultivada. De modo distinto a outras regiões, em que o termo é empregado para se referir à plantação de alimentos para consumo humano, especialmente grãos ou cereais, naquele contexto lavoura implica pastagem, não a nativa, mas a cultivada ${ }^{3}$. As lavouras têm sido um investimento recorrente dos produtores que, há poucas décadas, passaram a fazer queijo durante o ano todo. Antes disso, como já mencionado, o queijo era feito apenas na primavera e verão e o manejo do gado, especialmente durante os meses de inverno, era realizado de modo distinto, o que será detalhado a seguir.

\section{Só tirava leite no período em que a natureza permitia: mudanças no manejo do gado e a produção de queijo no verão}

Inicialmente, as propriedades da região tinham áreas grandes ou, até mesmo, áreas que comportavam características diferenciadas, incluindo tanto extensões de campo nativo quanto capões de mato, em regiões de encosta de serra. Assim, a partir da primavera, quando o campo começava a brotar, até o final do verão, o gado permanecia

\footnotetext{
${ }^{3}$ Entre as plantas utilizadas para a produção de pastagem cultivada, as mais citadas pelos produtores são aveia e azevém e, em alguns casos, trevo.
} 
na área de campo; no início do outono, quando as áreas de campo já não ofereciam nutrientes suficientes para os rebanhos, estes eram levados até as áreas de encosta de serra, onde ficavam protegidos do frio e dispunham de algum alimento. O ciclo fechavase ao final do inverno, com o deslocamento do gado para áreas de campo que, ao final do inverno, seriam queimadas para que, na primavera, já estivessem renovadas. No sistema antigo de manejo da propriedade, o queijo era produzido apenas na primavera e verão, mantendo-se, durante os meses frios, como relataram alguns interlocutores, apenas uma ou duas vacas próximas a casa, para haver leite para o consumo da família. Contudo, com as partilhas por herança, muitas propriedades ficaram localizadas em regiões predominantemente de campo ou de serra e, somado ao fato que, há cerca de uma década, vários produtores passaram a fazer queijo também nos meses de outono e inverno, o manejo do gado, particularmente das vacas destinadas à produção de leite, passou a sofrer alterações.

Essas mudanças na produção vêm acontecendo há poucas décadas e, embora não seja possível precisar exatamente a partir de quando se passou a produzir queijo durante o ano todo, alguns interlocutores apontam que esse processo iniciou há cerca de 30 anos, intensificando-se há cerca de dez anos.

Bom, quando eu cheguei aqui, ainda a tradição era só fazer queijo durante a primavera e verão. Trinta anos atrás começou a mudar isso, com o advento das pastagens [...]. Mais recentemente, há dez anos atrás, com batata, soja. Então essa troca aconteceu exatamente nesse momento. As pessoas não tiravam... raríssimas propriedades tiravam leite inverno e verão. Muito poucas. E as que tiravam no inverno e verão, normalmente entregavam pra Corlac de Taquara. Não fazia queijo, que daí já eram umas propriedades mais estruturadas. Mas a grande maioria só tirava leite no período em que a natureza permitia, dava pro gado alimentação que era possível, que eram as pastagens nativas. [...] Mas hoje praticamente o queijo é feito durante todos os meses do ano, mais ou menos. (Gerson, técnico)

A: Naquela época, mais era no verão só que nós fazia. Não fazia no inverno. Porque no inverno, faz pouco tempo que todo mundo tá fazendo queijo. Não faz nem dez anos eu acho, né, Josué? J: Não. No inverno, é. Porque daí tinha que tratar das vacas e daí já era muito mais difícil. Eles largavam os terneiros, apartavam. A: Tratavam, mas largavam os terneiros. Queijo era só no verão também. No inverno... Depois que começou a vir conta de luz por mês, conta disso por mês, é que daí todo mundo se obrigou, daí. Tem que ter uma renda para, né, tem que ter um salário para tu pagar isso aí, né. [risos] (Amélia e Josué, produtores) 
Como mencionou Gerson, só tirava leite no período em que a natureza permitia, ou seja, na primavera e verão, quando os campos nativos estão verdes e ricos em nutrientes. Nos meses de outono e inverno, em que a pastagem nativa não é suficiente para nutrir o rebanho, era preciso encontrar meios de garantir a alimentação do gado, especialmente das vacas utilizadas para a produção de leite e queijo durante o ano todo. A frase que inspira o título deste item, mencionada por Gerson, técnico na região, deixa implícita a ideia de que, para produzir leite o ano todo, é preciso investir na alimentação do gado, pois a natureza apenas permite alimentação abundante e nutritiva durante alguns meses do ano. A prática mais comum para a produção de leite nos demais meses é o emprego de lavouras, ou seja, de áreas de pastagem cultivada, que são plantadas ao final do verão, para que nos meses de outono e inverno se possa garantir a produção de leite. Além de pastagem cultivada, os produtores plantam também milho para a produção de silagem e, menos comumente, de grãos. Em alguns casos, compra-se ração. Outra prática que também está presente na região é o melhoramento de campo, que consiste em manejar o campo nativo de modo que, no outono e inverno, quando a pastagem natural é insuficiente, plantas cultivadas estejam disponíveis ${ }^{4}$. Mas é importante ter presente que, para os produtores tradicionais ${ }^{5}$, essas são medidas empregadas quando o campo não é suficiente para manter as vacas produzindo leite, pois primordialmente o campo nativo é considerado a melhor opção e, mesmo no inverno, quando os campos estão secos, é neles que as vacas passarão boa parte do tempo. O trato - silagem, milho ou ração - é oferecido aos animais durante a ordenha; no caso de emprego de pastagens cultivadas, após a ordenha, as vacas são soltas nessas áreas e mantidas ali por algumas horas para, logo em seguida, serem conduzidas às áreas de campo nativo, onde passarão o restante do dia e a noite.

Assim, se antes a lida com o gado envolvia o deslocamento dos animais no início do inverno para regiões de encosta de serra, agora, pelo menos para as vacas que compõem o rebanho que garantirá a produção de leite, esse deslocamento não mais

\footnotetext{
${ }^{4}$ Nesse caso, as plantas mais empregadas são aveia preta, azevém, trevo branco e vermelho e cornichão (EMATER/RS, [2007]).

${ }^{5}$ Ao longo deste artigo, referimo-nos aos produtores tradicionais de Queijo Serrano, diferenciando-os de "novos" produtores de queijo, que investem em sistemas mais intensivos para produção de leite e de queijo. Além de dimensões técnicas como, por exemplo, o emprego de gado comum, alimentado à base de campo nativo e a produção de queijo a partir de leite não aquecido ou não pasteurizado, os produtores tradicionais distinguem-se dos "novos" também por questões culturais e identitárias. Para discussão mais ampla a esse respeito, ver Cruz (2012) e Krone (2010).
} 
ocorre, e a preocupação passa a ser ter alimento suficiente para mantê-las produzindo leite durante os meses frios. Nesse sentido, a organização das propriedades tem crescentemente se conformado de acordo com a necessidade de alimentação do gado. Vejamos alguns depoimentos.

[E dessa área, uma parte é de lavoura, para roça?] C: Roça não, lavoura só. [E planta milho?] C: Mais milho e lavoura. R: E o restante é campo, mato. (Cássio e Rita, produtores)

[A gente viu ali outro dia que vocês plantam milho, tem as lavouras... o que mais que vocês cultivam, plantam?] Pasto e milho e o leite, né. Plantamos milho na época certa e o pasto. No mês de março, começa a plantar o pasto. Geralmente mês de março sempre tu reserva uma lavoura ali, mas que ela não fique muito cheia de milho pra mim plantar um pasto porque tu precisa ter um pasto no cedo. Porque às vezes uma vaca dá cria, ela adoece, qualquer uma coisa, e tu tem que botar no pasto. (Firmino, produtor)

Os depoimentos acima indicam que os produtores de Queijo Serrano organizam a propriedade de forma a garantir o sustento do gado, especialmente das vacas que serão ordenhadas. Como indicado por Firmino, a produção é pasto e milho $e$ leite, ou seja, tudo o que se produz na propriedade está associado à produção de leite e, portanto, a alimentação do gado passa a ser central. Durante o trabalho de campo, não vimos, na maioria das propriedades visitadas, plantações para o consumo da família e, mesmo no caso de haver plantações de milho, produto que, como no caso da propriedade de Firmino, é cultivado pela maioria dos produtores, este será frequentemente utilizado para a produção de silagem.

Desse modo, pode-se considerar que, uma vez que a produção de alimentos para o consumo não é significativa na região, é o queijo que garante, ao ser comercializado, a aquisição de alimentos para a família. Por essas razões, Vanice, produtora de queijo, durante caminhada por sua propriedade, enquanto explicava o manejo do gado, especialmente das vacas utilizadas para a ordenha, resumiu o sistema na seguinte frase: o homem do campo planta pro gado.

\section{$O$ gado no centro da vida}

O gado tem, portanto, papel central na organização das propriedades e na vida dos produtores, estando, inclusive, relacionado a momentos importantes, como o 
nascimento dos filhos. Exemplo disso é o costume que foi revelado por algumas famílias durante conversas informais. De acordo com esse costume, os filhos (especialmente os meninos), logo ao nascer, são presenteados, por seus padrinhos, com terneiros (termo empregado na região para se referir aos bezerros). Esse costume, explicaram as famílias, seria um estímulo para que, desde cedo, os homens fossem formando seu rebanho.

Este é o caso de Felipe que, durante a pesquisa de campo, completou 9 anos. Logo que nasceu, Felipe ganhou de seu padrinho alguns terneiros e agora, ao cavalgar e acompanhar o pai na lida com o gado, reconhece seus animais e os aponta, no rebanho. Felipe, apesar da pouca idade, está acostumado a participar das atividades desenvolvidas na propriedade.

Também é desde criança que se aprende a fazer o queijo, inicialmente ajudando e realizando pequenas tarefas e, em seguida, fazendo queijo eventualmente, quando os pais - ou mais especificamente a mãe - não estão em casa ou não podem fazê-lo. Este é o caso de Cássio que, do mesmo modo que Felipe, também ganhou seus primeiros terneiros quando bebê. Ao completar 15 anos, Cássio começou a fazer queijo do leite das vacas de seu próprio rebanho. Vejamos o trecho de entrevista em que Cássio explica essa trajetória.

[Em relação ao queijo, há quanto tempo vocês estão produzindo queijo?] $E u$ já produzia quando morava lá na minha avó. Desde... deixa eu ver... desde 99 eu comecei a fazer. Desde 99. [naquele ano o interlocutor tinha 15 anos]. Faz onze anos. [Começou ajudando?] Não, que eu comecei a fazer pra mim. Ajudando desde antes. [Daí tu ganhou o queijo?] É, daí eu comecei a fazer das minhas vacas. Desde 99. Mas que eu ajudo com o queijo, desde que eu era pequeno. Desde cinco, seis anos.

Se, desde que nascem os filhos, eles já têm relação com o gado, à medida que essa relação vai sendo nutrida, muitos jovens vão também apreendendo sobre as lidas na propriedade. Esses valores e conhecimentos, compartilhados desde o nascimento dos filhos, são elementos centrais para a continuidade da produção, pois o trabalho com o gado e a lida do queijo não são propriamente ensinados, mas compartilhados, de modo que, ao mesmo tempo em que ajudam, os filhos se apropriam dos conhecimentos e práticas e, no caso do Queijo Serrano, de sua "receita". 


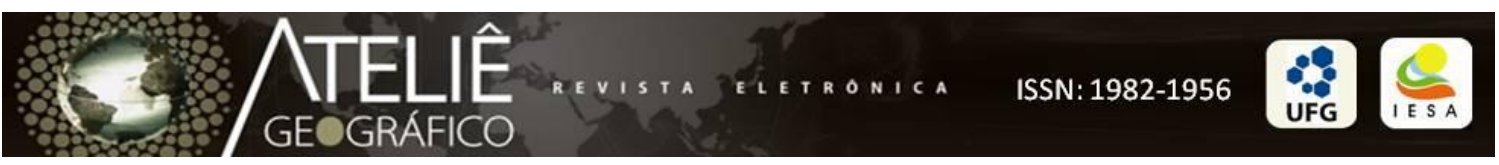

A transmissão do saber para o trabalho está em geral subordinada ao chefe de família que, ao transmitir saber, transmite mais do que técnicas, mas também valores e construção de papéis, como argumentam Woortmann e Woortmann (1997). Os mesmos autores, referindo-se ao contexto do Sertão Sergipano, consideram que, entre sitiantes, “[...] a transmissão do saber para o trabalho faz-se no próprio trabalho [...]" (WOORTMANN e WOORTMANN, 1997, p. 11). Do mesmo modo como percebido por esses autores em relação ao Sertão Sergipano, na região de produção do Queijo Serrano, como vimos argumentando, o manejo do gado e a produção do queijo são, desde cedo, acompanhados pelas crianças, em lida/trabalho que, nesse contexto, parece muitas vezes misturar-se ao prazer de compartilhar as tarefas dos adultos.

Essa relação entre trabalho e lazer é apontada por Krone (2009), que lembra a importância dos rodeios e torneios na região dos Campos de Cima da Serra. Nessas ocasiões, em que, entre outras atividades, há cavalgadas, provas de laço e montaria, o lazer imita a lida do campo. Ainda que referindo-se a situação distinta daquela encontrada nos Campos de Cima da Serra, Menezes (2009), em estudo sobre a produção de Queijo de Coalho no Sertão Sergipano, também aponta para a forte relação daqueles produtores com o gado e chama a atenção para a importância das vaquejadas, festa rural popular que, como afirma a autora, teria nascido da "[...] apartação do gado e da busca de animais na caatinga." (MENEZES, 2009, p. 50). Embora hoje, como afirma a autora, as vaquejadas já não tenham o objetivo de apartar o gado, “[...] o labor torna-se festa, a seriedade do trabalho como cumprimento da obrigação, torna-se alegria." (MENEZES, 2009, p. 51). Nesse caso, tal como nos Campos de Cima da Serra, as festas e momentos de lazer replicam o manejo do gado, reforçando a importância e significados desses animais para os produtores.

Como vimos, a organização da propriedade se dá em torno do manejo e alimentação do gado e esta lida estende-se, inclusive, a momentos de lazer e sociabilidade. Entre os produtos centrais dessa organização, está o leite, que permitirá a produção de queijo. Mas, mais do que isso, essa organização diz respeito também à manutenção de um modo de vida que, ainda que passando por mudanças, tem por objetivo a manutenção da terra. A terra, mais que um meio de trabalho para as famílias, tal como ensinam Woortmann e Woortmann (1997), é outra categoria central para 
apreender a lógica de vida dos camponeses e, neste caso, dos produtores de Queijo Serrano.

\section{A importância da terra e o cuidado com a natureza e com os animais}

Na região dos Campos de Cima da Serra, entre os produtores tradicionais, o cuidado com a terra e com os animais se expressa em várias situações do manejo e das práticas cotidianas desenvolvidas nas propriedades. Estar no meio rural e cuidar da terra são elementos centrais para a organização de suas vidas. Para ilustrar essa relação, vale tomarmos o caso da produtora Vanice, que contou que, mesmo quando morava na cidade, os finais de semana eram dedicados à propriedade da família, onde ainda viviam os pais do marido. Agora, com a sucessão das terras, o casal gerencia a parte da propriedade que lhes coube na herança. A produtora revelou ainda que os netos, de 13 e 4 anos, assim como a filha e o marido, que moram na cidade, vêm quase todos os finais de semana visitá-los e acrescentou, com orgulho, que as crianças gostam muito da lida do campo, de cavalgar, participar de rodeios e de fazer fogo de chão no galpão. Tendo feito essa declaração, Vanice avaliou que, se o gosto dos netos pelo campo e pelas lidas com o gado continuar, há esperança de que eles venham a morar no campo e é possível que, assim como ela e o marido fazem, eles continuem cuidando da terra.

A preocupação de Vanice com o futuro de sua propriedade pode ser explicada se tomarmos a análise de Woortmann (1990), que propõe a noção de campesinidade enquanto característica que pode estar presente em maior ou menor grau em distintos grupos rurais. $\mathrm{O}$ autor, que considera as categorias terra, família e trabalho como centrais e interdependentes no que se refere à noção de campesinidade, argumenta que "Nas culturas camponesas não se pensa a terra sem pensar a família e o trabalho, assim como não se pensa o trabalho sem pensar a terra e a família." (WOORTMANN, 1990, p.23).

\section{O manejo dos animais}




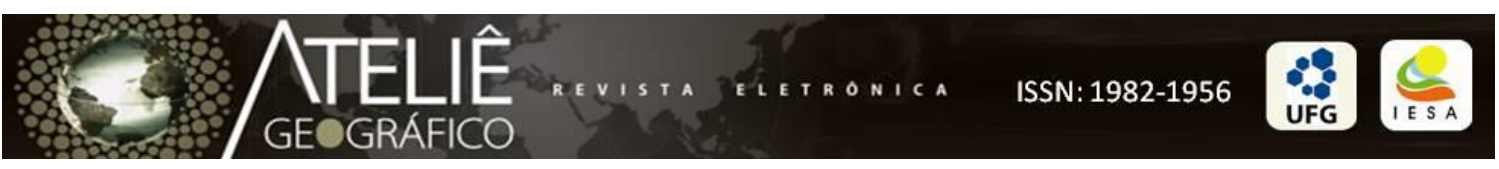

Além da terra que, como discutimos, é central para os produtores de Queijo Serrano, especialmente para aqueles que temos considerado produtores tradicionais, o trabalho também é central para os produtores dos Campos de Cima da Serra. Além do cuidado com a terra, o manejo feito especialmente em relação ao gado - ou seja, o modo de trabalho - vincula-se aos cuidados com as animais.

Uma primeira evidência do cuidado dedicado aos animais pode ser apreendida pelo fato de cada vaca empregada para a produção de leite possuir um nome, por meio do qual é chamada para o galpão na hora da ordenha. Mas, mais do que um nome - o que não foi observado em todas as propriedades e em relação a todas as vacas -, acompanhar a ordenha permitiu perceber que, em geral, os produtores organizam essa atividade de acordo com as características de cada vaca, de modo a facilitar o trabalho e criar um ambiente tranquilo para a ordenha, pois, do contrário, as vacas esconderiam o leite.

Além de conhecer as características de cada vaca, os cuidados no manejo se estendem também aos terneiros. $\mathrm{O}$ interesse dos produtores tradicionais não é especializar o rebanho - ainda que seja comum fazer melhoramento para aumentar a produção de leite, dar um choque, ou seja, cruzar com um touro de raça leiteira ou com um touro de raça mais resistente -, a intenção é manter o gado forte, bem adaptado à região e apropriado tanto para leite quanto para carne.

Assim, diferentemente do sistema de produção especializado em raças leiteiras, quando nascem machos, estes não são descartados, pelo contrário: do mesmo modo que as terneiras fêmeas, os machos são mantidos junto à mãe até estarem crescidos ou até a mãe ter outra gestação. De fato, a lógica que predomina no caso de produção de leite baseada em raças leiteiras é outra: não há necessidade de manter os terneiros machos com as vacas, pois aí o rebanho não possui duplo papel, o de produzir animais para a comercialização e o de produzir leite, como acontece no caso dos produtores tradicionais de Queijo Serrano. Nesse sentido, Jonas resume a questão:

É, o gado comum é um gado mais prá, prá criar, prá carne, é prá abate. Mas as minhas vacas comuns, gosto de tirar elas porque dai se criam, passam o inverno gordas e dá terneiro bom. A gente aproveita tudo, né. (Jonas, produtor) 


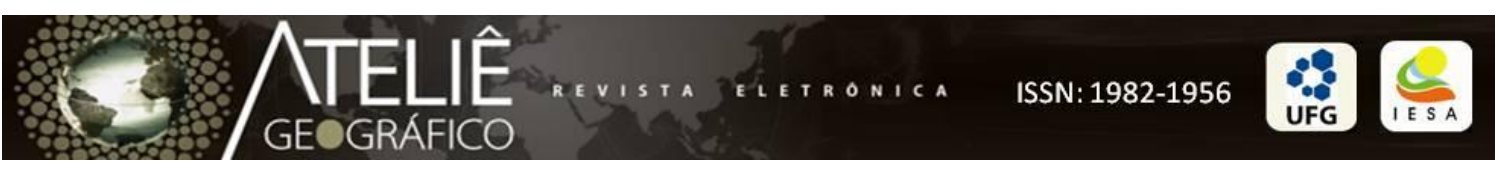

Em geral, na produção tradicional, o terneiro não é separado da mãe antes de seis meses de idade e, em alguns casos, esse período pode se estender até um ano. Nesse período, além de os terneiros serem fundamentais para a prática do apojo, como veremos a seguir, eles permitem que, no caso de a família se ausentar da propriedade, não haja problema em relação à ordenha, pois, nesse caso, são os terneiros que fazem o serviço.

\section{Os terneiros}

Os terneiros, fundamentais no sistema de ordenha tradicional, além de estimular a descida do leite da vaca, fazem a limpeza dos tetos. Mas, para que essa prática se mantenha, há uma série de cuidados em que, tão importante quanto a produção de leite, é o bem-estar dos terneiros. Quando o terneiro é pequeno, é comum que os produtores não tirem leite de um dos tetos da vaca para deixar mais leite para o recém-nascido. Como argumenta a produtora Amélia, é preferível fazer menos queijo a lograr o terneiro. Nós não gostamos de lograr os terneiros, né. Quando é novinho, ele tem que mamar bastante. Quando já estão maiores e, portanto, todos os tetos são ordenhados, os terneiros são mantidos por algum tempo, após a ordenha, junto às mães, quando, então, podem mamar o resto do leite que não foi ordenhado. Por volta do meio dia, são apartados, ou seja, separados das vacas, até a ordenha do dia seguinte.

O cuidado com a alimentação do terneiro está, evidentemente, relacionado com o duplo papel desse gado, empregado tanto para a produção de carne como para a produção de leite, como já discutimos. Porém, esse cuidado reflete também preocupação com o bem-estar dos animais, como fica evidenciado na fala do casal de produtores Amélia e Josué.

J: Aqui é oito meses, nove meses, que às vezes fica [o terneiro junto à mãe]. Daí a gente observa assim. Por exemplo, uma vaca pegou cria. Tem umas que se tu continuar tirando [leite], acho que elas continuam dando. A: São dengosas com os terneiros, sabe. Elas são amojadas e querem aquele terneiro ali. J: Daí tu pega, tira aquele terneiro ali pra dar um pouco de condição pra ela. Às vezes eu brinco em casa, mas também a coitada tá comendo trato pra três, né. Porque daí ela tem que dar leite pra nós, pro terneiro ao pé e pro outro que ela tem dentro da barriga. (Amélia e Josué, produtores). 


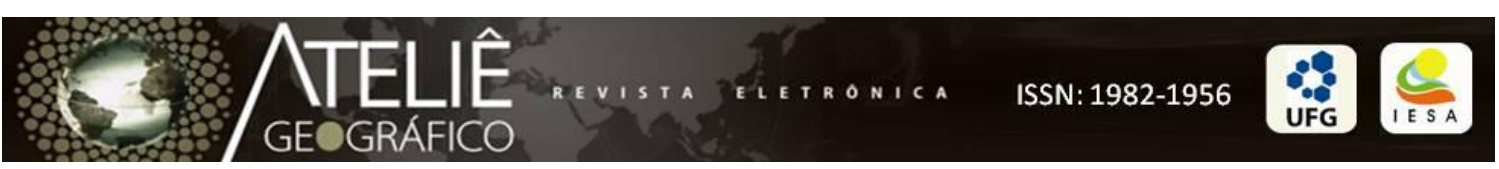

A preocupação de Amélia e Josué é tanto com as vacas como com os terneiros. As vacas amojadas, ou seja, prenhas, muitas vezes são dengosas e querem continuar com o terneiro já criado, para continuar alimentando-o. Nesses casos, Josué explica como faz o manejo:

Porque eles falam também assim em desmame precoce, que eles fazem. Aquilo ali é pra dar mais produção de terneiro, né. Se nós pegar, por exemplo, assim: tu aparta uma vaca cedo e deixa até de tarde sem terneiro, ela já dá uma reação ali também. É uma coisa que ela pega cria se ela tiver estado corporal, né. Não precisa tu apartar, né. Daí repete cria estando com terneiro ao pé, né. E dai isso é manejo que a gente faz, né. (Josué, produtor).

Amélia contou ainda, em tom de reprovação, que alguns vizinhos estariam apartando terneiros novinhos. A fala da produtora elucida a insatisfação quanto ao manejo adotado:

Nós temos uns vizinhos aqui que fizeram desmame, tão fazendo, começaram faz uns três anos atrás, fazer desmame com dois meses o terneirinho. Mas dá dó. Porque daí pra tu fazer isso aí tu tem que dar atenção pro bichinho pra dali ele se criar. Daí eles só apartam, daí é verão vão deixando, vão deixando. Daí, quando chega no inverno os bichinhos já tão fraquinhos, magrinhos... (Amélia, produtora).

Outro casal de produtores, Cássio e Rita, revelam que, além de dar mais serviço e requerer mais alimentação, fazer duas ordenhas ao dia não compensa, pois se o terneiro é criado junto à mãe, ele dará renda no ano seguinte, ao ser comercializado.

[E vocês tiram o leite só pela manhã?]C: Isso. Não, não. É bem no tradicional mesmo. R: Tirar leite à noite não dá. C: Além de muito serviço, vai muito trato, daí. Não tem descanso. É complicado, que assim a gente cria o terneiro junto, que vai te dar uma renda daqui um ano. Tu vende ele, né. Se tu tirar duas vezes por dia, já não faz uma coisa nem outra. (Cássio e Rita, produtores)

Mas, além desse argumento, os produtores consideram que, ao tirar leite duas vezes ao dia, o terneirinho sofre bastante também. Embora haja um fim econômico em manter o terneiro junto à mãe, pois, desse modo, obtém-se leite e, ao final de um ano, um novilho pronto para a venda, a preocupação em atender bem aos terneiros e mantêlos por mais tempo junto às respectivas mães, cuidado presente na fala da maioria dos produtores, revela preocupação com o bem-estar dos animais, tanto dos terneiros quanto das vacas. 


\section{Do queijo, o soro para alimentar a criação}

Outra característica recorrente na produção de queijo é o destino do soro. Enquanto na produção industrial o soro, resíduo líquido da produção de queijo, é um efluente que requer destino adequado por ser altamente poluente, no caso do Queijo Serrano o soro não representa impacto ambiental, pois, como a produção ocorre em escala condizente com a estrutura das propriedades, o efluente é coletado e destinado à alimentação de porcos e terneiros, vacas e mesmo animais domésticos, como cachorros. Esse aproveitamento do soro é também evidenciado em outros contextos onde há produção artesanal de queijo no Brasil.

Meneses (2008), em documento elaborado para subsidiar o reconhecimento do Queijo Minas como patrimônio cultural imaterial do Brasil pelo Instituto do Patrimônio Histórico e Artístico Nacional (IPHAN), apresenta que, no caso da produção de queijo Minas Artesanal, um produtor explicou que, em fazenda que não tem produção de queijo, até os cachorros são magros. Por meio dessa afirmação, o interlocutor de Meneses estaria fazendo alusão ao fato de que, sem produção de queijo, não há soro, de modo que os animais domésticos e os de criação, como porcos e aves, seriam privados desse alimento.

Do mesmo modo, Menezes (2009) relata a importância do soro na produção de Queijo de Coalho e afirma que, no caso de Sergipe, em que é comum a produção desse queijo em fabriquetas, os produtores de leite, em geral familiares dos donos desses empreendimentos, vendem o leite para as fabriquetas, mas com a condição de que, ao final da produção diária, a fabriqueta devolva o equivalente ao leite vendido em soro. Essa prática, fortemente presente na região estudada por esta autora, é mantida, pois naquele contexto o soro é fundamental para a alimentação dos porcos que, por sua vez, contribuem para a renda das famílias.

Voltando aos Campos de Cima da Serra, vários foram os produtores que indicaram a importância do soro em suas propriedades. Vejamos, a título de ilustração, o trecho da entrevista da produtora Clarisse, que, como tantos outros, usa o soro para a alimentação de porcos e outros animais. 
E tu vê, daí o leite... do queijo saí o leite pros porco, né, sai pros cachorro... tem prá alimentação dos bicho, né. Sobra pros outros, né. Dá pra muita coisa, né. Sobra dinheiro. [...] Tiro o leite, sobra o soro, tu faz aproveitamento com o porco. Se tu não tem porco, tu dá pros terneiro, tu faz alguma coisa. Dá pros cachorro. (Clarisse, produtora).

Em outras propriedades, os interlocutores explicaram que, antes de dar o soro para os porcos, era possível deixá-lo parado de um dia até o outro, para retirar a nata, empregada para fazer mistura ${ }^{6}$ ou para comer durante o café com mistura.

\section{Conhecimentos tradicionais e patrimônio cultural}

O cuidado com a terra, o manejo dos animais e o destino do soro indicam a presença, permeada por conhecimentos tradicionais e práticas adotadas pelos produtores, de um sistema em que as várias dimensões da produção, trabalho e vida estão articuladas. Nesse sistema, há, entre outras, interdependência entre insumos e matérias-primas. A escala de produção do Queijo Serrano, que emprega os recursos da propriedade e, na mesma propriedade, promove o manejo dos resíduos, torna possível garantir o manejo diferenciado dos animais, bem como o destino dos efluentes, pois, no âmbito da unidade produtiva familiar, como procuramos evidenciar, as etapas de produção estão integradas.

Durante o trabalho de campo, alguns produtores mencionaram a importância de respeitar as fases da lua para fazer podas, cortar árvores, plantar, cuidar do rebanho, etc. Assim foi que Josué explicou que os antigos sabiam muito mais sobre as épocas certas da lua. Referindo-se ao momento de cortar árvores para obter madeira, o produtor ponderou que:

[...] se tu falar para um agrônomo em lua, ele te chama de louco. É crendice. Mas ele diz assim: "Se tiver adubo e tiver semente e a terra pronta, não tem lua." Mas se tu plantar na lua, modifica. Uma batatinha, se plantar no estilo de antigamente e tu colher ela na lua cheia, ela não murcha. Tu pode deixar cinco meses a batata lá num cantinho, suja de terra... (Josué, produtor).

\footnotetext{
${ }^{6}$ Mistura são os ingredientes que compõem uma das refeições presente na mesa dos produtores: o café com mistura. Pode-se incluir aí, além do café e do leite, pão, biscoitos, rosca, cuscuz, queijo e também, em alguns casos, comidas que sobraram da refeição anterior.
} 


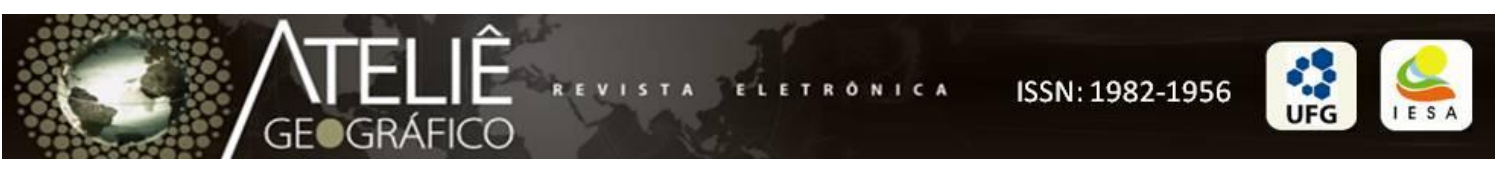

Nesta discussão, cabe retomar a noção de campesinidade, segundo a qual terra, família e trabalho se justapõem para que, por meio do trabalho na terra, seja assegurada a manutenção da família. Woortmann (1990), ao propor essa noção, não se referia a um grupo específico, indicando que a campesinidade estaria presente, em maior ou menor grau, em distintos grupos rurais. No caso de produtores de Queijo Serrano dos Campos de Cima da Serra, onde o modo de produção do queijo é fortemente associado ao modo de vida de famílias rurais, podemos argumentar que há elementos de campesinidade, uma vez que as características evidenciadas indicam que o manejo dos animais e da propriedade diz respeito a um amplo sistema, que integra as diversas atividades desenvolvidas nas propriedades a conhecimentos e práticas compartilhadas e reproduzidas, ainda que em diferentes níveis, pelas famílias produtoras.

Esse modo de vida, de trabalho, de cuidado com os animais e com a terra pode também ser tomado à luz das reflexões de Fonte $(2008 ; 2010)$. De acordo com essa autora, em países ou regiões onde a modernização da agricultura não foi muito intensa, as culturas agrícolas e alimentares e as relações locais não chegaram a ser totalmente extintas, de modo que estratégias para o desenvolvimento rural têm sido fundamentadas no reconhecimento, valorização e legitimação de práticas e modos de produção já existentes. Este é o caso, como procuramos evidenciar, dos Campos de Cima da Serra, onde as práticas de manejo e trabalho seguem lógica própria que, ainda que influenciada por técnicas e práticas convencionais, mantém um modo particular de operar, que integra conhecimentos tradicionais e recursos disponíveis nas propriedades. No que se refere à produção de alimentos, essas características apontam para a "valorização da origem dos alimentos", perspectiva que, como sugere Fonte (2008; 2010), emerge vinculada a contextos em que conhecimentos locais estão conservados.

No que diz respeito à valorização de alimentos tradicionais, cabe menção ao trabalho que vem sendo desenvolvido pelo Instituto do Patrimônio Histórico e Artístico Nacional (IPHAN) em relação ao reconhecimento de bens culturais imateriais. Ainda que no Brasil a proteção de bens culturais de valor histórico e artístico não seja recente - há pelo menos 50 anos é prática consolidada -, até a pouco, o único instrumento legal era o tombamento, aplicável apenas a bens materiais, como, por exemplo, monumentos, prédios e obras de arte. 


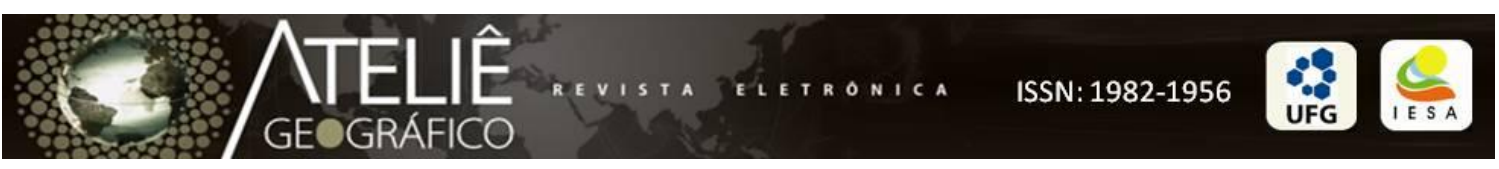

A partir de meados da década de 1970, entretanto, uma nova abordagem para a preservação de bens culturais, fundamentada na noção de referência cultural, passou a ser introduzida no país. Em consequência, manifestações culturais, especialmente presentes nas classes populares, passaram a ser compreendidas como patrimônio cultural imaterial. Essa noção, com base em uma concepção antropológica de cultura, enfatiza a diversidade não apenas da produção material como também dos sentidos e valores atribuídos pelos diferentes sujeitos a bens e práticas sociais (LONDRES, 2000). "Falar em referências culturais nesse caso significa, pois, dirigir o olhar para representações que configuram uma 'identidade' da região para seus habitantes, e que remetem à paisagem, às edificações e objetos, aos 'fazeres' e 'saberes', às crenças, hábitos, etc." (LONDRES, 2000, p. 14).

A mesma autora considera, ainda, que as discussões acerca da noção de referência cultural fundamentaram a definição de patrimônio cultural presente no Artigo n²16 da Constituição Federal de 1988 (BRASIL, 1988), considerada por Santilli (2009) como um avanço significativo, na medida em que permite incluir entre os bens culturais passíveis de serem reconhecidos como patrimônio cultural - por meio do Decreto $\mathrm{n}^{\circ} 3.551$ (BRASIL, 2000) - as formas de expressão, os modos de criar, fazer e viver e as criações científicas, artísticas e tecnológicas dos diferentes grupos sociais brasileiros. De acordo com esse instrumento, é importante ter presente que o registro refere-se aos modos de fazer, não ao produto final.

Entre os bens já registrados, cabe mencionar o Modo artesanal de fazer Queijo de Minas, nas regiões do Serro e das serras da Canastra e do Salitre, registrado em junho de 2008. Ainda, vale também mencionar o recente registro, em 2010, do Sistema Agrícola Tradicional do Rio Negro ${ }^{7}$. Esse sistema agrícola, estabelecido em torno do cultivo da mandioca brava (Manihot esculenta), está associado a mais de 22 povos indígenas localizados ao longo do rio Negro, na região Amazônica, e à ampla diversidade agrobiológica, mantida por meio de complexas redes sociais. Na concepção de patrimônio cultural, os sistemas agrícolas referem-se à interconexão entre várias dimensões, como explica Emperaire et al. (2010).

\footnotetext{
${ }^{7}$ Para mais informações sobre o registro do Modo artesanal de fazer Queijo de Minas o do registro do Sistema Agrícola Tradicional do Rio Negro e demais bens imateriais registrados no Brasil, acessar <http://www.iphan.gov.br/bcrE/pages/indexE.jsf\#>.
} 
Entender "sistema agrícola" implica em dar conta de como se imbricam na agricultura as dinâmicas de produção e reprodução dos vários domínios da vida social, incluindo-se aí os múltiplos significados que vão se constituindo ao longo das vivências e experiências históricas, orientadoras dos processos de construção de identidades. Os saberes constitutivos dos sistemas agrícolas e as atividades que os caracterizam resultam de processos, constantemente reelaborados, sendo o tempo presente apenas um momento em sua trajetória. (EMPERAIRE et al., 2010, p. 19).

De acordo com essa definição, para além da diversidade e relação entre práticas, técnicas e conhecimentos com os processos de construção de identidade, o fator temporal, mencionado pela autora traz um novo elemento. Nesse sentido, é clara a perspectiva de que esses sistemas não são entendidos como estáticos no tempo e impermeáveis a mudanças, mas estão em constante re-elaboração.

Em resumo, o registro do Sistema Agrícola Tradicional do Rio Negro coloca novas possibilidades para o reconhecimento de saberes como patrimônio, pois para além de modos de fazer, como o caso de bens anteriormente registrados, incluindo aí o Queijo de Minas, essa perspectiva reforça a importância de um conjunto de conhecimentos, fazeres, práticas, tecnologias, instrumentos e artefatos relacionados ao cultivo, transformação e consumo de alimentos que, no caso do Sistema Agrícola do Rio Negro, está fundamentado na mandioca.

Tomando como inspiração a abordagem por meio da qual foram analisadas as características do Sistema Agrícola Tradicional do Rio Negro, poderíamos argumentar que o Queijo Serrano, mais que um produto com características específicas associadas a fatores naturais e humanos particulares, diz respeito a um amplo conjunto de saberes e práticas que, como discutimos, está associado ao modo de vida dos produtores e ao manejo dos animais. Embora não tenha sido nosso objetivo neste artigo explorar outras questões associadas à produção de Queijo Serrano, cabe mencionar que essa produção está, ainda, associada às técnicas, utensílios e experiência para a produção do queijo, aos critérios de definição de qualidade e redes de sociabilidade associadas à escolha dos queijos e ainda, ao manejo do campo ${ }^{8}$. Desse modo, para além de um produto, o Queijo Serrano é, ao mesmo tempo, consequência e constituinte de um sistema mais amplo que, para que seja preservado, deve ser reconhecido e, de algum modo, protegido, em suas diversas dimensões.

\footnotetext{
${ }^{8}$ Para discussão mais ampla a respeito das dimensões associadas à produção de Queijo Serrano, ver Cruz (2012).
} 


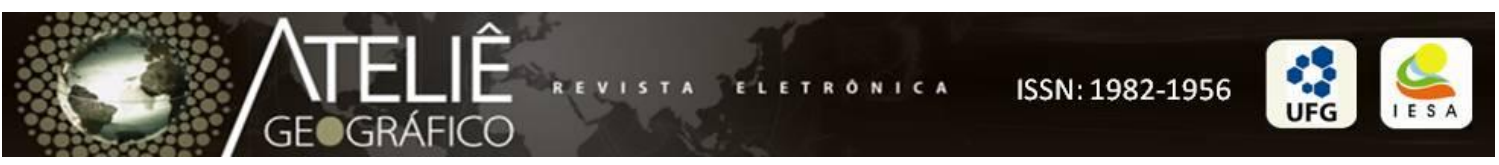

Ainda que o caso do Queijo Serrano não possa ser comparado ao da diversidade agrobiológica que fundamenta o Sistema Agrícola do Rio Negro, o que importa reter é que tampouco o contexto de produção de Queijo Serrano pode ser valorizado em sua totalidade pelo uso de instrumentos que tomam em conta antes o produto final do que todo o contexto em que o produto está imerso. Se analisados à luz de parâmetros outros que os empregados na própria região, as diversas dimensões associadas à produção e consumo de Queijo Serrano perdem sentido. Por isso, mais que obter o reconhecimento de um produto, trata-se de legitimar os conhecimentos de produtores, moradores, enfim, das pessoas que dão sentido ao local, conferindo significado e significância ao produto ali produzido.

\section{Considerações finais}

Como procuramos argumentar ao longo deste artigo, há, nos Campos de Cima da Serra, além do manejo de plantas empregadas especialmente para a alimentação do gado, também forte relação entre técnicas, práticas, conhecimentos e sociabilidade intimamente associados à produção de Queijo Serrano e à identidade e modos de vida dos produtores rurais. Essas características reforçam a pertinência de identificar instrumentos legais para a proteção de sistemas tradicionais, que permitam, ao mesmo tempo, a valorização e o reconhecimento do papel dos agricultores responsáveis por reproduzir conhecimentos e práticas que dão sentido a sistemas como este.

Para tanto, a perspectiva associada ao registro de bens imateriais pode ser profícua, embora seja preciso considerar que, ao mesmo tempo em que novas perspectivas se abrem a partir do registro de bens de natureza imaterial como proposto pelo IPHAN, colocam-se também alguns desafios. Entre eles, conjuntamente ao registro de bens imateriais, emergem questões relacionadas aos direitos autorais e à propriedade intelectual coletiva, ao consumo e circulação dos bens, particularmente naqueles aspectos implicados nas relações de mercado, pois, como explica Alves (2011), o registro tem valor declaratório e, portanto, não cria direitos de qualquer espécie.

Por essa razão, além do registro, importante instrumento para a valorização e legitimação desses bens, sua proteção requer não apenas a atuação conjunta com outros instrumentos como também, como argumenta Alves (2011), a criação de regime 
jurídico específico para a proteção de conhecimentos tradicionais. Nesse sentido, Santilli (2009), que discute o sistema jurídico em relação à agrobiodiversidade no contexto brasileiro, explica que essa proteção pode se dar por meio de duas convenções: a Convenção para a Salvaguarda do Patrimônio Cultural Imaterial e a Convenção sobre a Proteção e Promoção da Diversidade das Expressões Culturais, ambas já incorporadas ao sistema jurídico brasileiro. A primeira define a noção de patrimônio cultural imaterial, enquanto a segunda convenção reconhece a importância de conhecimentos tradicionais e sua relação positiva com o desenvolvimento sustentável e a necessidade de proteção e promoção não apenas desses conhecimentos como também da diversidade de expressões culturais.

De modo associado à pertinência do registro de bens de natureza imaterial para a valorização de alimentos tradicionais, é importante retomar os argumentos de Fonte $(2008 ; 2010)$, autora que, referindo-se ao contexto rural europeu, considera que o reconhecimento, valorização e legitimação de formas tradicionais de conhecimento e de práticas e modos de produção já existentes dizem respeito também a estratégias para o desenvolvimento rural.

Essas perspectivas que apontam para a importância da preservação de alimentos tradicionais, ainda que fundamentadas em diferentes contextos e abordagens teóricas, estão em harmonia quanto à necessidade e relevância de valorização e proteção de formas de conhecimento tradicional, especialmente no que diz respeito aos espaços rurais, evidenciando, assim, a centralidade da preservação desses conhecimentos e, em decorrência, dos produtos - como é o caso dos alimentos tradicionais - ali gerados.

\section{Referências Bibliográficas}

ALVES, Ana Cláudia Lima. A comida como patrimônio cultural. Revista de Economia Agrícola, São Paulo, v. 58, n. 1, p. 73-86, 2011.

BARNES, John. A. Redes sociais e processo político. In: FELDMAN-BIANCO, Bela (Org.). Antropologia das sociedades contemporâneas. São Paulo: Ed. Global Universitária, 1987. p. 159-193.

BRASIL. Constituição da República Federativa do Brasil de 1988. Presidência da República, Casa Civil. Disponível em:

<http://www.planalto.gov.br/ccivil_03/Constituicao/Constituicao.htm>. Acesso em 26 jun. 2012. 
BRASIL. Decreto $\mathrm{n}^{\circ}$ 3.551, de 04 de agosto de 2000. Institui o Registro de Bens Culturais de Natureza Imaterial que constituem patrimônio cultural brasileiro, cria o Programa Nacional do Patrimônio Imaterial e dá outras providências. Diário Oficial [da] República Federativa do Brasil, Poder Executivo, Brasília, DF, 07 ago. 2000. Seção 1, p. 2. Disponível em:

<http://www.in.gov.br/imprensa/visualiza/index.jsp?jornal=1\&pagina=82\&data=07/08/ 200>. Acesso em: 14 abr. 2012.

CRUZ, Fabiana Thomé da. Produtores, consumidores e valorização de produtos tradicionais: um estudo sobre qualidade de alimentos a partir do caso do Queijo Serrano dos Campos de Cima da Serra - RS. 2012. Tese (Doutorado em Desenvolvimento Rural) - Programa de Pós-Graduação em Desenvolvimento Rural, Universidade Federal do Rio Grande do Sul, Porto Alegre, 2012.

EMATER/RS. Programa regional de melhoramento de campo nativo. Campos de Cima da Serra do Rio Grande do Sul. [2007]. 1 folder. Apoio Agrimar Produtos e Máquinas Agrícolas.

EMPERAIRE, Laure et al. O sistema agrícola tradicional do Rio Negro. Dossiê de Registros. Brasília, 2010.

EMPERAIRE, Laure; VELTHEM, Lúcia H. V.; OLIVEIRA, Ana Gita. Patrimônio cultural imaterial e sistema agrícola: o manejo da diversidade agrícola no médio Rio Negro, Amazonas. In: Reunião Brasileira de Antropologia, 26., 2008, Porto Seguro. Anais. Porto Seguro: ABA, 2008.

FONTE, Maria. Knowledge, food and place: a way of producing, a way of knowing. Sociologia Ruralis, v. 48, n. 3, p. 200-222, 2008.

FONTE, Maria. Food relocalisation and knowledge: dynamics for sustainability in rural areas. In: FONTE, Maria; PAPADOPOULOS, Apostolos G. (Ed.). Naming food after places: food relocalisation and knowledge dynamics in rural development. Farnham: Ashgate, 2010. p. 1-35.

KRONE, Evander Eloí. Identidade e cultura nos Campos de Cima da Serra (RS): práticas, saberes e modos de vida de pecuaristas familiares produtores do Queijo Serrano. 2009. Dissertação (Mestrado em Desenvolvimento Rural) - Programa de PósGraduação em Desenvolvimento Rural, Universidade Federal do Rio Grande do Sul, Porto Alegre, 2009.

KRONE, Evander Eloí; MENASCHE, Renata. Identidade e cultura nos Campos de Cima da Serra (RS): práticas, saberes e modos de vida de pecuaristas familiares produtores do Queijo Serrano. Ateliê Geográfico, v. 4, n. 10, p. 61-85, 2010.

LONDRES FONSECA, Maria Cecília. Referências culturais: base para novas políticas de patrimônio. Inventário nacional de referências culturais: manual de aplicação. Brasília: Instituto do Patrimônio Histórico e Artístico Nacional, 2000. p. 11-21. 
LONDRES, Cecília. Sistemas agrícolas locais como patrimônio cultural. Muito prazer Brasil, 2010. Disponível em: <http://muitoprazerbrasil.blogspot.com/2010/11/mariacecilia-londres-fonseca-sistemas.html>. Acesso em 20 mar. 2012.

MENESES, José Newton Coelho. Queijo Artesanal de Minas: Patrimônio Cultural do Brasil. Dossiê interpretativo. v. 1. Belo Horizonte. 2006. Disponível em http://portal.iphan.gov.br/portal/baixaFcdAnexo.do?id=892. Acesso em 16 mai. 2008.

MENEZES, Sônia de Souza Mendonça. A força dos laços de proximidade na tradição e inovação no/do território sergipano das fabriquetas de queijo. 2009. Tese (Doutorado em Geografia) - Núcleo de Pós-Graduação em Geografia. Universidade Federal de Sergipe, São Cristóvão, 2009.

SANTILLI, Juliana. Agrobiodiversidade e direitos dos agricultores. São Paulo: Peirópolis, 2009.

WOORTMANN, Klaas. "Com parente não se neguceia": o campesinato como ordem moral. Anuário Antropológico 87, Rio de Janeiro, 1990, p. 11-73.

WOORTMAN, Ellen; WOORTMANN, Klaas. O trabalho da terra: a lógica e a simbólica da lavoura camponesa. Brasília: Ed. Unb, 1997.

\section{Agradecimentos}

À Coordenação de Aperfeiçoamento de Pessoal de Nível Superior (CAPES) pela bolsa de estágio de doutoramento no Reino Unido oferecida à primeira autora deste artigo (Processo CAPES n 02/10/2316). 